\title{
Linfocentros abdominal, lumbar y pelviano en el carpincho (Hydrochoerus hydrochaeris, Linnaeus 1766)
}

\author{
Bode, F.F.; Cao, J.A. ${ }^{1}$ Resoagli, J.M..; Resoagli, E.H. ${ }^{1}$; Millán, S.G..; Flores Quintana, C. ${ }^{2}$ \\ ${ }^{1}$ Cátedra Anatomía Comparada Primera Parte, ${ }^{2}$ Cátedra Histología y Embriología, Facultad de Ciencias \\ Veterinarias, UNNE, Sargento Cabral 2139, Corrientes (3400), Argentina. Tel/Fax: 03783-425753. \\ E-mail: anato1@vet.unne.edu.ar
}

\begin{abstract}
Resumen
Bode, F.F.; Cao, J.A.; Resoagli, J.M.; Resoagli, E.H.; Millán, S.G.; Flores Quintana, C.: Linfocentros abdominal, lumbar y pelviano en el carpincho (Hydrochoerus hydrochaeris, Linnaeus 1766). Rev. vet. 19: 2, 158-160, 2008. La utilización del cuero y carne de carpincho constituye un importante recurso económico regional. Con el objeto de conocer la ubicación anatómica de los linfocentros abdominal, lumbar y pelviano, se disecaron nueve carpinchos, describiéndose el número de nódulos linfáticos, su tamaño y sus relaciones con las estructuras vecinas. También se detalla su estructura histológica, que resultó semejante a la de los ganglios linfáticos de los mamíferos domésticos. Estos grandes roedores son actualmente criados en cautiverio con fines productivos. Para ser liberada al consumo, su carne debe ser bromatológicamente apta, para lo cual resulta útil la inspección de los ganglios linfáticos, cuya ubicación topográfica es un tema escasamente abordado en los tratados clásicos de anatomía.
\end{abstract}

Palabras clave: Hydrochoerus hydrochaeris, anatomía, linfocentros.

\begin{abstract}
Bode, F.F.; Cao, J.A.; Resoagli, J.M.; Resoagli, E.H.; Millán, S.G.; Flores Quintana, C.: Abdominal, lumbar and pelvic lymphocenters of the "carpincho" (Hydrochoerus hydrochaeris, Linnaeus 1766). Rev. vet. 19: 2, 158-160, 2008. Leather and meat of "carpincho" (Hydrochoerus hydrochaeris L.) constitute an important regional economic resource in northeastern Argentine. To determine the abdominal, lumbar and pelvic anatomical location of lymphocenters, nine cadaveric preparations were studied. Number, size and relationship with neighbor structures were determined. Histological structure of lymph nodes was similar to that of domestic mammals. Nowadays, these big rodents are raised in captivity for productive purposes. For human consumption, carpincho's meat must be bromatologically acceptable, and the inspection of lymphocenters must be performed.
\end{abstract}

Key words: Hydrochoerus hydrochaeris, anatomy, lymphocenters.

\section{INTRODUCCIÓN}

El conocimiento del sistema linfático reviste particular interés en mamíferos domésticos y silvestres, por la importancia que asume en la inspección de carne para consumo humano. El carpincho (Hydrochoerus hydrochaeris, Linnaeus 1766) no escapa a esta premisa dado que actualmente este roedor de gran tamaño es criado en cautiverio con fines productivos.

La necesidad de contar con la sistematización anatómica del sistema linfático del carpincho contrasta con la escasa información disponible sobre el tema. La bibliografía encontrada sobre anatomía de Hydrochoerus hydrochaeris, reporta conocimientos sobre las estructuras de los órganos contenidos en las cavidades

Recibido: 8 agosto 2008 / Aceptado: 29 octubre 2008 abdominal y pelviana, así como del aparato reproductor ${ }^{3,8,9}$, pero no se hallaron investigaciones que hagan referencia a las estructuras anatómicas del sistema linfático. En cambio, para otras especies de interés bromatológico por el consumo de su carne, existe amplia información, especialmente sobre las estructuras linfáticas de la región abdominal 1,2,4-6,12 .

Las normas bromatológicas exigen la inspección sistemática de los nódulos linfáticos según cada especie animal $^{7,11}$. Así se establece que desde el punto de vista de la inspección de carnes, el estudio de los linfocentros y nódulos linfáticos de la región del abdomen son imprescindibles para determinar el estado sanitario de las carnes para su consumo.

El presente trabajo forma parte el proyecto PI-23 (SGCYT-UNNE) cuyos objetivos son describir las estructuras morfológicas del sistema linfático del carpin- 
cho, investigación orientada a la implementación de estrategias sanitarias que optimicen la comercialización de la carne y sus derivados.

\section{MATERIAL Y MÉTODOS}

Se disecaron 9 cadáveres de carpinchos. Seis de ellos provenían de la Dirección de Fauna y Flora de la Provincia de Corrientes y los tres restantes del Criadero Experimental de Carpinchos del INTA-Mercedes (Corrientes, Argentina). Practicada la necropsia con el animal en decúbito dorsal, previa evisceración del contenido abdomino-pelviano, se procedió al reconocimiento y disección de las diferentes estructuras anatómicas de la región. Los nódulos linfáticos fueron valorados en número, forma, tamaño y relaciones con las estructuras vecinas. Muestras de tejido linfoide fueron

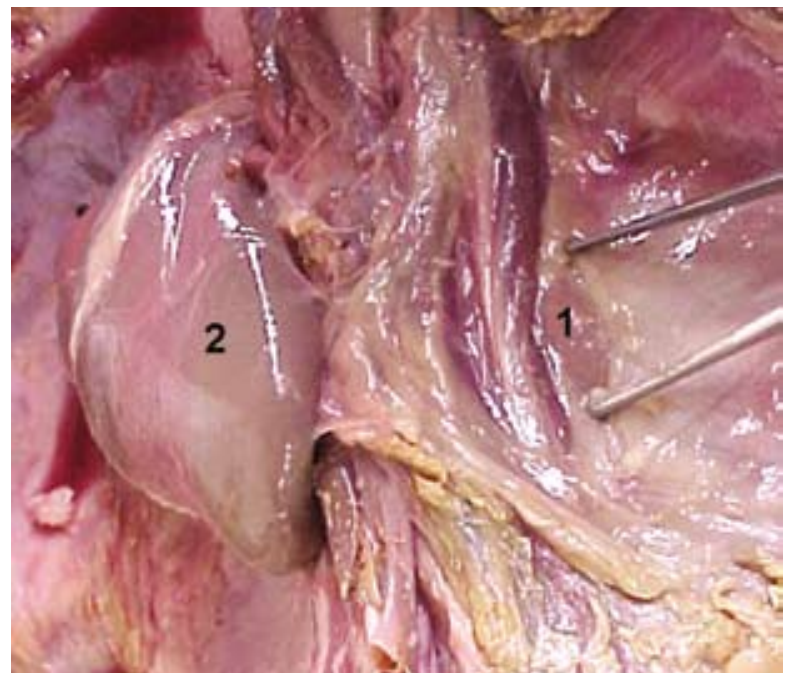

Figura 1. 1: nódulo linfático frénico abdominal, 2: riñón derecho (desplazado).

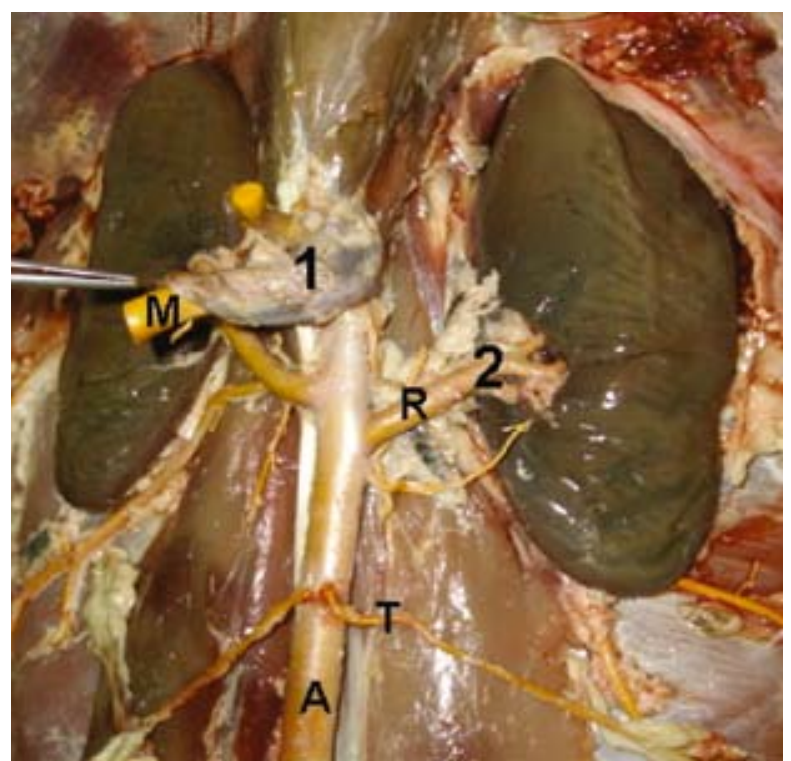

Figura 2. A: arteria aorta, R: arteria renal, M: arteria mesentérica craneal, T: arteria testicular, 1: nódulo linfático celíaco mesentérico, 2: nódulos linfáticos renales. procesadas para estudios histológicos por microscopía óptica. Todos los hallazgos fueron documentados fotográficamente.

\section{RESULTADOS Y DISCUSIÓN}

En la región sublumbar, extendida desde la primera vértebra lumbar (L1) hasta la base del sacro, fueron reconocidos los nódulos linfáticos correspondientes al linfocentro de los troncos lumbares, que se describen a continuación.

El nódulo linfático frénico abdominal (Figura 1) es de forma ovoide y está situado en caudal de los pilares del diafragma, cubierto por los riñones, en ventral de L1 y en correspondencia con el borde lateral del músculo psoas mayor, con una longitud aproximada de 18 $\mathrm{mm}$ de largo por $10 \mathrm{~mm}$ de ancho. El nódulo linfático

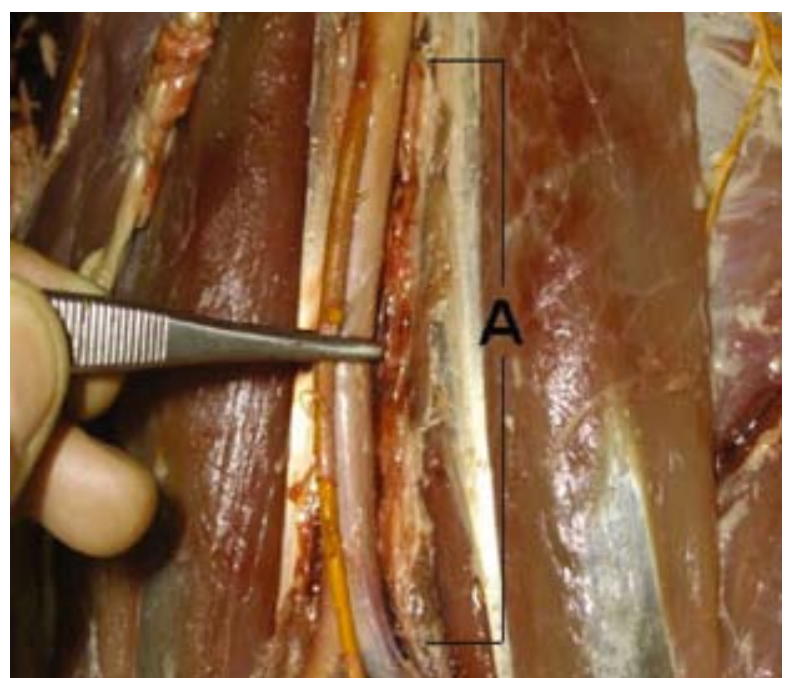

Figura 3. A: nódulos linfáticos aórticos lumbares.

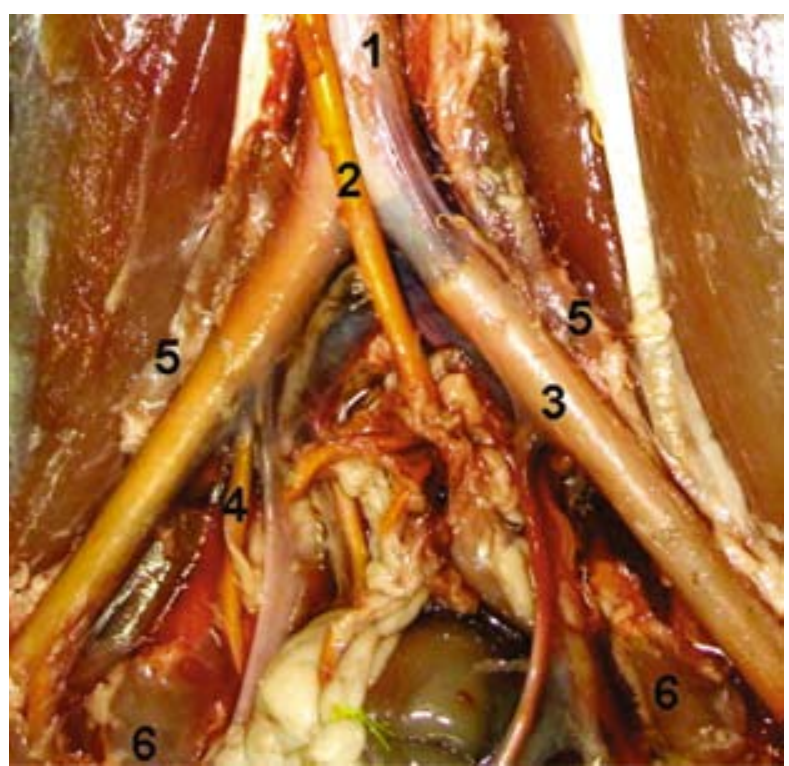

Figura 4. Arteria aorta caudal, 2: arteria mesentérica caudal, 3: arteria ilíaca, 4: arteria pudenda interna. 5: nódulo ilíaco lateral, 6: nódulo ilíaco medial. 
celíaco mesentérico (Figura 2:1) se sitúa en caudal del precedente, en el origen de las arterias celíacas y mesentéricas.

Los nódulos linfáticos renales (Figura 2:2) se ubican en el hilio renal, situados en el trayecto de las arterias renales, rodeados de tejido adiposo. Son de forma ovoidea y existen en número de 5 a 6 ( 2 en el riñón derecho y 3-4 en el izquierdo), con una longitud aproximada de 6 a $7 \mathrm{~mm}$.

Los nódulos linfáticos aórticos lumbares (Figura 3) son 6 a 8 pequeños nódulos, de 9 a $32 \mathrm{~mm}$ de longitud y $9 \mathrm{~mm}$ de ancho, situados a ambos lados de la arteria aorta y vena cava caudal, cubiertos en parte por tejido graso, extendidos desde los riñones hasta la bifurcación de la aorta. Se observaron además algunos nódulos linfáticos aplicados contra los músculos sublumbares.

Los nódulos linfáticos ilíacos mediales (Figura 4) existen en número de 3 a 4 , son de forma ovoidea, relativamente voluminosos y están situados en medial de la arteria ilíaca, próximos a su origen. El nódulo linfático ilíaco lateral (Figura 4) es relativamente grande, de 35 $\mathrm{mm}$ de largo por $5 \mathrm{~mm}$ de ancho y se sitúa en lateral del trayecto de la arteria ilíaca, próximo a la bifurcación aórtica.

La histología de los nódulos linfáticos reveló una arquitectura que responde en general a aquélla observada en los mamíferos domésticos, con clara diferenciación de las regiones cortical y medular. Por otro lado, las estructuras linfoideas macroscópicas observadas en la región abdominal del carpincho se asemejan en general a las descriptas para los porcinos ${ }^{10} \mathrm{y}$ para las otras especies domésticas 1,2, 4-6, 12. Se concluye que, por su localización parietal, los nódulos linfáticos descriptos resultan de fácil acceso a la inspección bromatológica.

\section{REFERENCIAS}

1. Chaveau A. 1905. Traitè d'Anatomie Comparée des Animaux Domestiques, Ed. Fils, Paris.

2. Ellenberger W, Baum H. 1849. Anatomie Descriptive et Topographique du Chien, Ed. Reinwald, Paris.

3. Escobar A, González-Jiménez E. 1971. Explotación semidoméstica del chigüire (Hydrochoerus hydrochaeris hydrochaeris). Informe Final Proyecto CONICIT DF030S1, Universidad Central de Venezuela, $17 \mathrm{p}$.

4. Getty R.1982. Anatomía de los Animales Domésticos, $5^{\circ}$ ed., Salvat, Barcelona.

5. Gonzáles J, González R. 1961. Anatomía Comparada de los Animales Domésticos, $7^{\circ}$ ed., Gráficas Canales, Madrid.

6. Harrison BM. 1969. Disección del Gato, Acribia, Zaragoza.

7. Mayer HF. 1984. Bromatología, Eudene, Resistencia (Chaco, Argentina).

8. Mendoza TH. 1984. Tórax del chigüire (Hydrochoerus hydrochaeris hydrochaeris): cavidad, análisis y topografía de órganos y trayectos vasculonerviosos. Tesis de ascenso, Universidad Central Venezuela, Caracas, $45 \mathrm{p}$.

9. Ojasti J. 1973. Estudio Biológico del Chigüire o Capiba$\mathrm{ra}$, Ed. Fondo Nacional de Investigaciones Agropecuarias, Caracas, $27 \mathrm{p}$.

10. Saar IL. 1982. Anatomía de los animales domésticos, $5^{\circ}$ ed, Interamericana, México.

11. Servicio Nacional de Sanidad Animal (SENASA). 1968. Reglamento de inspección de productos, subproductos y derivados de origen animal (Decreto Ley 4238/68). On line: www.senasa.gov.ar/Archivos/File/File753-capitulos. $p d f$.

12. Sisson S, Grossman JD. 1963. Anatomía de los Animales Domésticos, $4^{\circ}$ ed., Salvat, Barcelona. 